CLINICAL ETHICS

\title{
Off-label administration of drugs to healthy military personnel. Dubious ethics of preventive measures
}

\author{
D O E Gebhardt
}

J Med Ethics 2005;31:268. doi: 10.1136/ime.2004.008821

A lthough there are exceptions, the principle of primum nil nocere remains the cornerstone of the practice of medicine. In the well known handbook, Goodman and Gilman's The Pharmacological Basis of Therapeutics ${ }^{1}$ a case is presented which raises doubts about the permissibility of offlabel administration of certain drugs to healthy troops as a preventive measure. The following citation from this handbook gives a clear description of the problem:

Prophylaxis in cholinesterase inhibitor poisoning. Studies in experimental animals have shown that pretreatment with pyridostigmine reduces the incapacitation and mortality associated with "nerve agent" poisoning, particularly for agents, such as soman, that show rapid aging. The first large-scale administration of pyridostigmine to human beings occurred in 1990 in anticipation of nerve-agent attack in the Persian Gulf. At an oral dose of $30 \mathrm{mg}$ every 8 hours the incidence of side effects was around $1 \%$, but fewer than $0.1 \%$ of the subjects had responses sufficient to warrant discontinuing the drug in the setting of military action. Long term follow-up indicates that veterans of the Persian Gulf campaign that [sic] had received pyridostigmine showed a low incidence of a neurologic syndrome now termed the Persian Gulf Syndrome. It is characterized by impaired cognition, ataxia, confusion, myoneuropathy, adenopathy, weakness, and incontinence.

It should be noted that pyridostigmine is registered (onlabel) for use in patients with myasthenia gravis. In such patients the above mentioned side effects were either not observed or did not appear in such a serious manner.

Another example of possible off-label use of a drug for the "protection" of military personnel was reported in various Dutch national and regional newspapers on 2 March 2004. It concerns the drug, modafinil, which is registered for treatment of patients who have narcolepsy. ${ }^{2}$ The report coincided with a trial of two Dutch marines, who had been found asleep while supposedly on watch in Iraq. The newspapers also mention that the Dutch Ministry of Defence had asked an applied science institute (the Netherlands Organisation for Applied Scientific Research TNO) to investigate whether modafinil could be used to suppress the natural need of sleep for long periods of time (up to 50 hours). It was suggested that this drug had been given to American soldiers during the war in Iraq. As was to be expected the Dutch union of military personnel has raised objections to this off-label use of modafinil. One reason was that so far nothing is known about the long term effects of the drug on healthy personnel.

\section{COMMENTS}

It is well known that before a drug is registered, various studies have to be performed. First of these is the phase I study, which is the initial safety trial usually conducted in normal male volunteers. ${ }^{3}$ It is doubtful whether any ethics committee or institutional review board ${ }^{4}$ will allow such a trial with healthy volunteers to take place. On the other hand, in case of emergency, each country has the duty to protect its combatants. Thus it is clear that legislation is needed in this field of preventive medicine.

Correspondence to: D O E Gebhardt; doe.gebhardł@planet.nl

Received 19 March 2004

Accepted for publication 10 June 2004

\section{REFERENCES}

1 Hardman JG, Limbird LE, eds. Goodman and Gilman's The Pharmacological Basis of Therapeutics, 10th edn. New York: McGraw-Hill, 2001;188.

2 "Modafinil". In: Martindale: The Complete Drug Reference, 33rd edn. Sweeman SC, ed. London: Pharmaceutical Press, 2002:1512.

3 Spilker B. Guide to Clinical Trials. New York: Raven Press, 1991:xxii.

4 Spilker B. Guide to Clinical Trials, Chapter 27 (Informed consent and ethics committee/institutional review board processes). New York: Raven Press, 1991:202-18. 